\title{
The methodologies and strategies for the development of novel material systems and coatings for applications in extreme environments - a critical review
}

\author{
Marina Urbina ${ }^{1}$, Antonio Rinaldi ${ }^{2}$, Santiago Cuesta-Lopez ${ }^{3}$, Arcadii Sobetkii ${ }^{4}$, Anca Elena Slobozeanu ${ }^{4}$, \\ Peter Szakalos ${ }^{5}$, Yi Qin ${ }^{6}$, Mythili Prakasam ${ }^{7}$, Radu-Robert Piticescu ${ }^{4}{ }^{*}$, Cedric Ducros ${ }^{1}$, and Alain Largeteau ${ }^{7}$ \\ ${ }^{1}$ Commisariat à l'Energie Atomique et aux Energies Alternatives, Laboratoire d'Innovation pour les Technologies des Energies \\ Nouvelles CEA-LITEN, 17 rue des Martyrs, 38054 Grenoble Cedex 9, France \\ 2 Agenzia Nazionale per le Nuove Technologie, l'Energia e lo Sviluppo Economico Sostenabile-ENEA, Casaccia Research Centre, \\ Via Anguillarese 301, 00123 Rome, Italy \\ 3 ICAMCyL Foundation, 24492 Cubillos del Sil (León), Spain \\ ${ }^{4}$ National R\&D Institute for Nonferrous and Rare Metals-IMNR, 102 Biruintei Blvd., 077145 Pantelimon-Ilfov, Romania \\ ${ }^{5}$ Kungliga Tekniska Hoegskolan, Brinellvagen 8, 10044 Stockholm, Sweden \\ ${ }^{6}$ Centre for Precision Manufacturing, Dept. of DMEM, The University of Strathclyde,75 Montrose Street, Glasgow G1 1XJ, UK \\ 7 CNRS, Univ. Bordeaux, ICMCB, UMR 5026, 33608 Pessac, France
}

Received: 29 November 2017 / Accepted: 13 March 2018

\begin{abstract}
The aim of this paper is to present a critical analysis of existing methodologies, approaches and strategies used to develop materials systems and coatings for uses in extreme environments. The extreme or harsh conditions encompass a large variety of in-service forms such as: extreme temperatures, abrasion, corrosion, impact and radiation that can exist in various applications such as those associated with aerospace and aeronautical engineering, land and marine transport, manufacturing machinery, and even microelectronics products. This article describes how working environment and required service performance of a particular part or structure could affect the choice of materials and surfaces to which it is composed. In addition, the paper explains the relevance that abusive working environments have for industry, especially relating to their costs, being followed by an overview of surface deposition approaches that are currently popularly used to improve performance of mechanical devices that need to combat adverse conditions. Finally, a material system and three kinds of protective coatings that could be used in applications in extreme conditions are described. The critical review is an outcome of the strategic review from the EU H2020 SUPERMAT project which deals with materials and manufacture for the products/structural parts used in extreme conditions.
\end{abstract}

Keywords: extreme environment / material system / surface treatment / coating / economic impacts / case study

\section{Extreme environment and material-related issues}

A harsh environment could be any environment that impedes the operation of a device/system. Many types of the conditions could be considered to be harsh, such as: extreme pressure/temperature, shock, vibration, chemical reactivity, radiation, corrosion and humidity, ranging from the applications in, such as alloy production, component manufacture, transport and biomedical implants [1] while

\footnotetext{
* e-mail: radu.piticescu@imnr.ro
}

the energy sector faces additional harsh environment such as that in various power plants [2], some of such examples being listed below:

- Transport: Automobiles and airplanes that are operated in extreme conditions, being exampled by engines components and high-friction paired parts;

- Energy: The devices/pipelines/components used for energy conversions, transports and storages, which faces high-temperature, various kinds of mediums and nuclear/chemical reactions, and suffer from corrosion and fatigue failures;

- Manufacturing: Tools (e.g. cutting tools, dies and moulds, welding tools, high-temperature nozzles, etc.) used in manufacturing processes; 
Table 1. Typical service conditions and corresponding surface treatment techniques.

\begin{tabular}{|c|c|c|}
\hline Type of Treatment & Treatment Technique & Service Condition \\
\hline \multirow{3}{*}{ Surface Modification } & Metallic Cementation & \multirow{2}{*}{$\begin{array}{l}\text { Corrosion } \\
\text { Friction/Mechanical Wear }\end{array}$} \\
\hline & Anodic Oxidation Process & \\
\hline & Physical Vacuum Deposition & \multirow{3}{*}{$\begin{array}{l}\text { Corrosion } \\
\text { Friction/Mechanical Wear } \\
\text { Thermal Barrier }\end{array}$} \\
\hline \multirow{2}{*}{ Dry Deposition } & Thermal Spraying & \\
\hline & Vacuum Plating & \\
\hline \multirow{2}{*}{ Wet Deposition } & Electroplating & \multirow{2}{*}{ Corrosion } \\
\hline & Electroless Plating & \\
\hline
\end{tabular}

- Health: medical implants that can resist to bacteria and are of general biocompatibility, etc.

Material and process innovation is essential for the development of novel mechanical components and devices for uses in harsh environments. Nevertheless, the materials to be used in a device with specified performance and a given application may vary, depending on the environment in which a particular task is to be fulfilled. High-tech applications are frequently needed in harsh, aggressive environments and with the rapid expansion of technological applications. A wide range of future opportunities related to harsh environment applications can be foreseen. The number of materials that could be used in extreme environments is, however, still limited, largely due to that they are restricted by some specific requirements for the uses in these conditions.

Radical improvements in the performance and reliability of materials operating under extreme conditions would give industry a competitive edge in many high-value markets. At the same time, surface modification and coating offer the possibility to deliver materials which tolerate extreme environments at sustainable costs. Some coatings are already widely used in industry and represent a market worth in excess of $£ 10$ billion per annum. Table 1 depicts the surface treatments and surface modifications that can be used to combat with extreme environments. Nevertheless, effectiveness of these techniques and efficiency of developing these special surfaces would rely largely on the deep understanding of interactions of the materials surfaces (treated and untreated) with the harsh environments at the different length-scales such as atomistic and molecular level, taking into account multiphysics/phases influences. In return, such efforts could also lead to development of new surface/material systems with tailored functionalities specifically for combating a particular environment $[2,3]$.

\section{Typical extreme conditions and associated impacts on economy}

This section provides some statistics data showing impacts on the economy, in terms of the problems associated with extreme conditions as well as the measures taken to address these problems. Some typical extreme conditions, suitable materials and associated applications are listed in Table 2.

\subsection{Corrosion}

It was estimated that the effort for dealing with the corrosion costed approximately $\$ 2.5$ trillion globally, which is about $3.4 \%$ of the worth of the world's gross domestic produces, according to the NACE international [7]. On the other hand, it emphasizes on the importance of implementing best practice to combat the corrosion, which could lead significant impacts on the economy [8]. Figure 1 shows how the corrosion impacts on different economic sectors: drinking water and sewerage systems, motor vehicles and defence systems are the most highly affected. Figure 2 shows the corrosion-lead costs for the five industrial sectors in the USA. These demonstrate importance of preventing the corrosion and controlling its development processes.

\subsection{Friction}

Friction could give negative effect leading to degradation and emission. Its effects on the economy are difficult to be estimated since this is a widespread phenomenon. Some estimated data, nevertheless, does reflect the scale of the effects: for example, it was estimated that for some industries, approximately $30 \%$ of the production cost could be counted for replacement of the worn parts or 
Table 2. Summary of material types associated with extreme requirements and corresponding applications [1].

\begin{tabular}{|c|c|c|c|}
\hline Extreme environement & Extreme condition & Type of materials & Application \\
\hline \multirow[t]{2}{*}{ Corrosion } & Corrosive Environments & $\begin{array}{l}\text { Smart coatings (organic, } \\
\text { inorganic or hybrid): Self- } \\
\text { healing, antifouling, super- } \\
\text { hydrophobic }\end{array}$ & $\begin{array}{l}\text { Radar systems, satellites, laptops, } \\
\text { mobile phones, solar panels, } \\
\text { medical devices and implants, } \\
\text { invisible paints, furniture, } \\
\text { automotive, etc. }\end{array}$ \\
\hline & $\begin{array}{l}\text { Highly Corrosive } \\
\text { Solutions }\end{array}$ & Diamond Like Carbon & $\begin{array}{l}\text { Photo thermal converters of solar } \\
\text { energy, Medical prostheses, } \\
\text { Mechanical cutting tools [4] }\end{array}$ \\
\hline \multirow{4}{*}{ Temperature } & $\begin{array}{l}\text { Vacuum and High- } \\
\text { Temperature } \\
\text { Applications }\end{array}$ & Glasses and Glass-Ceramics & Solid Oxide Fuel Cells [5] \\
\hline & $\begin{array}{l}\text { High Temperature } \\
\text { Applications }\end{array}$ & Intermetallic and Alloys & Aero-engines, automotive \\
\hline & Very low Temperature & & Fibre bragg gratings \\
\hline & Ultrahigh Temperatures & Refractory Materials & $\begin{array}{l}\text { High-temperature furnaces, } \\
\text { manufacturing tools, thermal } \\
\text { shields, engines, reactors. }\end{array}$ \\
\hline \multirow{4}{*}{ Friction } & Wear & $\begin{array}{l}\text { Protective Hard Coatings } \\
\text { (Carbides, Ceramics, } \\
\text { Tufflon and Traclon) }\end{array}$ & Tribological applications \\
\hline & Shock Waves & Visco-elastic polymers & Impact protection \\
\hline & Shock high acceleration & & $\begin{array}{l}\text { Military applications, measurement } \\
\text { devices }\end{array}$ \\
\hline & High Pressure & $\begin{array}{l}\text { Multi-ferroics materials } \\
\text { alternative membrane } \\
\text { material }\end{array}$ & $\begin{array}{l}\text { AC/DC magnetic field sensors } \\
\text { photovoltaic multiferroic solar cell } \\
\text { sensors for automotive and process } \\
\text { industries }\end{array}$ \\
\hline \multirow{4}{*}{$\begin{array}{l}\text { Space extreme } \\
\text { conditions }\end{array}$} & High-Radiation Fields & Diamond Like Carbon & MEMs \\
\hline & Radiation & Radiation-Tolerant Oxides & Semiconductors sensors, transistors \\
\hline & High Magnetic Field & Magnetoelastic Materials & Sensors [6] \\
\hline & High Electric Field & Ceramic dielectrics & Satellites, space-borne weapons \\
\hline
\end{tabular}

repairing [9]. Some source even mentioned that $1 \sim 2 \%$ of the GDP of a nation could go to dealing with friction associated problems, etc. Further cost is associated with energy cost, e.g. higher forming or cutting forces required due to the friction, lower engine efficiency resulted from the friction, etc. and hence, reducing the friction in some typical applications could lead to significant energy savings $[10,11]$. Correspondingly, reducing the friction in some energy systems and vehicles also leads to the reduction of $\mathrm{CO} 2$ emissions. It was reported that properly dealing with tribology issues could have saved $€ 13.2$ billion for Spain alone in 2014, being about $1.4 \%$ of the country's GDP [12].

\subsection{Extreme temperatures}

It is very difficult to estimate the global cost of the damage, caused in various industrial sectors, by extreme operating temperatures (very high or very low). The transport and energy sector are two typical sectors that are seriously affected by the needs of operating in extreme temperatures, which has been commonly known for their conventional products and systems. The effects of extreme temperatures in service for new products and new energy systems such as electric vehicles and Li-ion Battery [13] are, nevertheless, less discussed.

The performance of an electric vehicle on its acceleration and range will be severely affected in a cold condition, being considerably lower due to poor ion-transport in the batteries which affects the energy efficiency. Two discharge curves for MCMB-NCO Li-ion test-cells with electrolytes, at a room temperature and $-20^{\circ} \mathrm{C}$, are shown in Figure 3 [14], which indicates the discharge behaviour differences. At the same time, under a high-temperature condition, air conditioning could consume more power which would lead to a reduction of the vehicle range.

Other applications such as microelectronics are also affected by the temperature which influences system reliability [15]. In the temperature range -55 to $150^{\circ} \mathrm{C}$, most reported failure mechanisms are not due to a steadystate temperature, but they occur either due to temperature gradient, temperature cycle magnitude, or rate of change of temperature. For photovoltaic conversion, the operating temperature is a significant parameter: both 

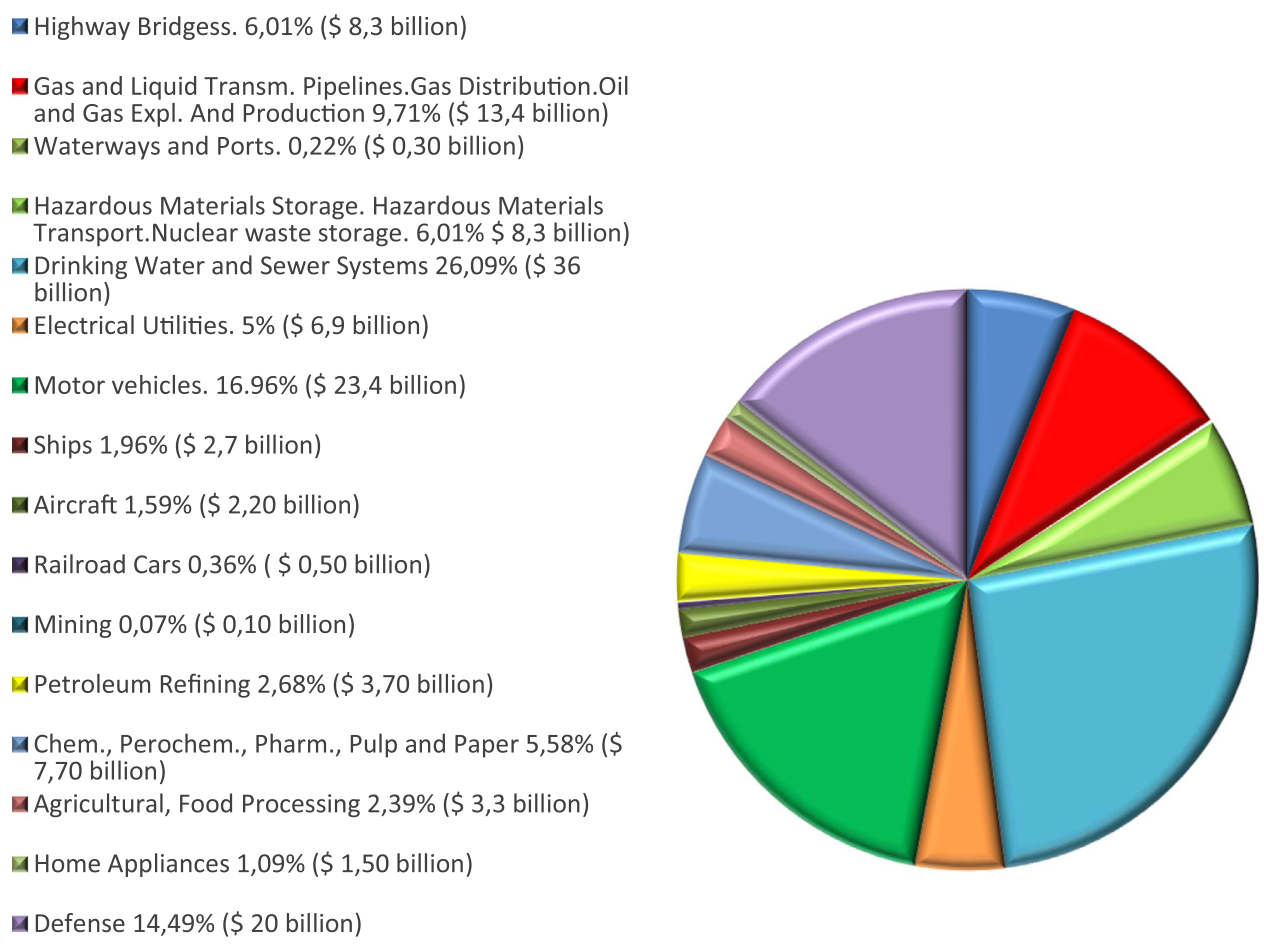

Fig. 1. Corrosion costs per economic sector [8].

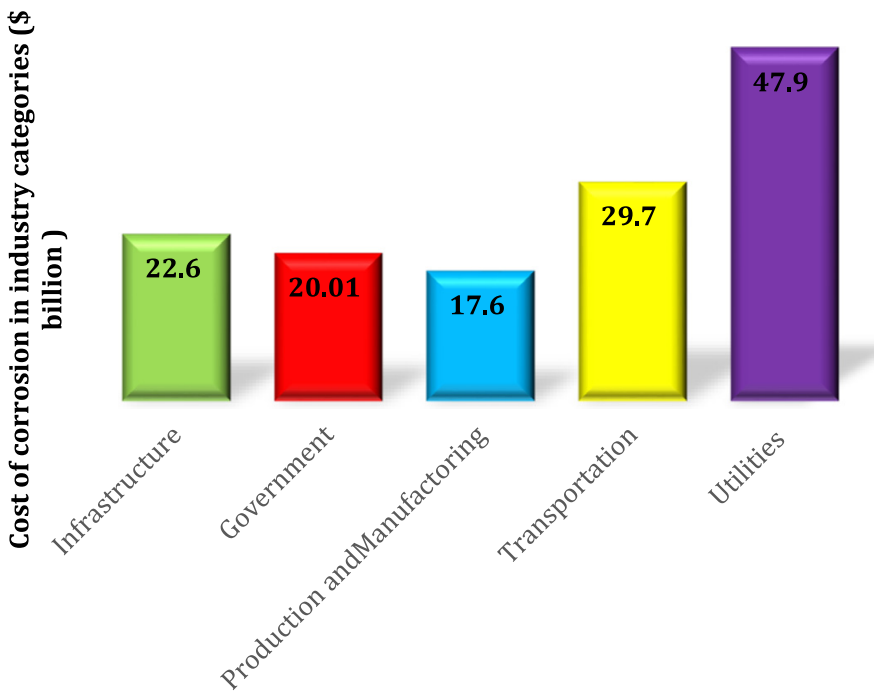

Fig. 2. Corrosion costs by industrial categories [8].

electrical efficiency and hence, power output of a PV module, could decrease linearly with the operating temperature, according to the literature [16].

\subsection{Space environment}

To estimate the economic impact of extreme space-weather (variable conditions on the sun and space that influence performance of the technologies used on Earth) many factors and scenarios have to be taken into account. The results of an analysis of the effect of weather extremes on the electricity transmission infrastructure in USA estimated the economic costs to be as high as $\$ 1 \sim 2$ trillion in the first year, being equivalent to a so-called "global Hurricane Katrina". Disturbances of the space weather in the upper atmosphere and near-Earth could influence/ disrupt a wide range of technological systems [17,18], e.g., electricity transmission infrastructures [19], and loss of satellites due to the damaged electronics or increased orbital drag [20]. Good understanding of a severe spaceweather event that might occur is essential for disaster planning related scenarios [21].

Different tactics could be considered to counteract the effects of extreme or harsh conditions and improve the resistance of materials systems and structures to extreme 


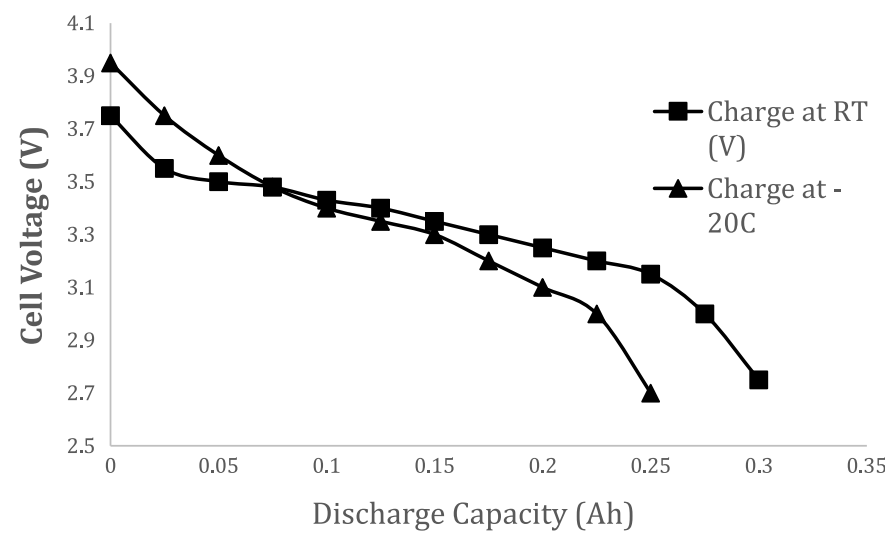

Fig. 3. Discharge curves for Li-ion test cells [14].

conditions. Improving choice of materials (chemically inert materials, dense materials to reduce the effect of radiation, or material combinations and new alloys are among the best materials systems options), manufacturing technology (additive manufacturing, coatings and thin nanostructured layers with improved adhesion, reduced delamination and increased resilience), the use of chemically inert materials for packaging, isolation of the electronics from the harsh environment (for example, using Phase Change Materials), are among the potential approaches to neutralise the adverse effects of extreme conditions. Another possible strategy is to use extreme environment inhibitors, including that for barrier protection, cathodic protection, anodic passivation, active corrosion inhibition and self-healing.

\section{Surface treatments to enhance performances of engineering surfaces}

Well established techniques for surface modification of particular matter are liquid phase processes like electrochemistry or sol gel methods and gas phase processes like fluidized beds, chemical vapour deposition (CVD). Their unquestionable advantage is the complete embedding of the particles to be coated within the protective coatings. For instance, the electrolyte or the gas which permeates the suspended particles in a fluidized bed [22]. Nonetheless, often the choice of coating material is limited, for instance by the conductivity of the substrate, or by the availability of electrolytic solutions, or by the existence of a suitable precursor gas.

Physical vapour deposition (PVD) and especially magnetron sputtering, on the other hand, allows for basically a free choice of deposition material. Materials can be deposited regardless of their melting point and oxides, or nitrides or carbides can be formed by choosing reactive processing routes.

\subsection{Thin-film deposition methods}

Thin films are used in diverse technological applications, such as surface protection and decoration, data storage, and optical and microelectronic devices. The increasing demand for new functional films has been a strong incentive for research towards not only understanding the funda- mentals and technical aspects of thin film growth, but also developing new deposition techniques which allow for better control of the deposition process [23].

Table 3 summarizes application requirements and characteristics of thin-film deposition processes, with a comparison of the main thin film processes depending on features such as: substrate temperature, deposition rate, uniformity, film density, grain size and level of impurities. Thermal evaporation is the most inexpensive process but thickness uniformity and film density are very poor and impurity level very high. Superior quality methods are LPCVD, providing very good uniformity and film density at a very low impurity level but at high cost.

\subsection{Physical vapour deposition (PVD)}

The PVD is a well-known surface coating method based on which several processes have been developed and widely used. The processes that are relevant to the coatings for being used in extreme conditions include evaporation, cathodic arc deposition and sputtering. The applications of PVD method and processes techniques ranges over a wide variety of applications from decorative, to high temperature superconducting films. The thickness of the deposits can vary from angstroms to millimeters. Very high deposition rates $(25 \mu \mathrm{m} / \mathrm{sec})$ have been achieved with the advent of electron beam heated sources. A very large number of inorganic materials metals, alloys, compounds, and mixtures as well as some organic materials can be deposited using PVD technologies.

Hard coatings often refer to the surfaces with high hardness which is of several merits for contacting elements [25]. For those to be applied in an extreme condition such as high contact force acting on a cutting tool, these coatings play significant roles in enhancing tool performance and extending the tool life. Deposition of hard coatings on the substrate materials has been enabled with several PVD processes such as magnetron sputtering, electron-beam deposition, cathodic-arc vapour deposition (arc-ion plating or plasma). These work in different ways, in terms of vapour conversion from a solid coating material as well as delivery of the vapour to the surface where the coating material is to be deposited.

As an emerging technology, high-power pulsed magnetron-sputtering (HPPMS) has attracted a great attention. In HPPMS, or HIPIMS (high-power impulse magnetron-sputtering), the power is applied with pulsed modes, e.g. duty-cycle $(<10 \%)$ and frequency $(<10 \mathrm{kHz})$, which would result in a power density of up to several $\mathrm{kWs} / \mathrm{cm}^{-2}$. This would lead to ultra-dense plasmas generated, the merits of which include high-degree ionization of the sputtered atoms and off-normal transport of the ionized species, with respect to the target. These improvements would help to improve the coating ability, e.g., dense and smooth coatings onto a complex-shaped substrate, to add the process control flexibility for tailored properties and hence, elemental and compound films could be optimized $[23,26]$.

The benefit of using HPPMS lies in the fact that the substrate temperature during the deposition process is kept low which opens an opportunity for applications with TCO 


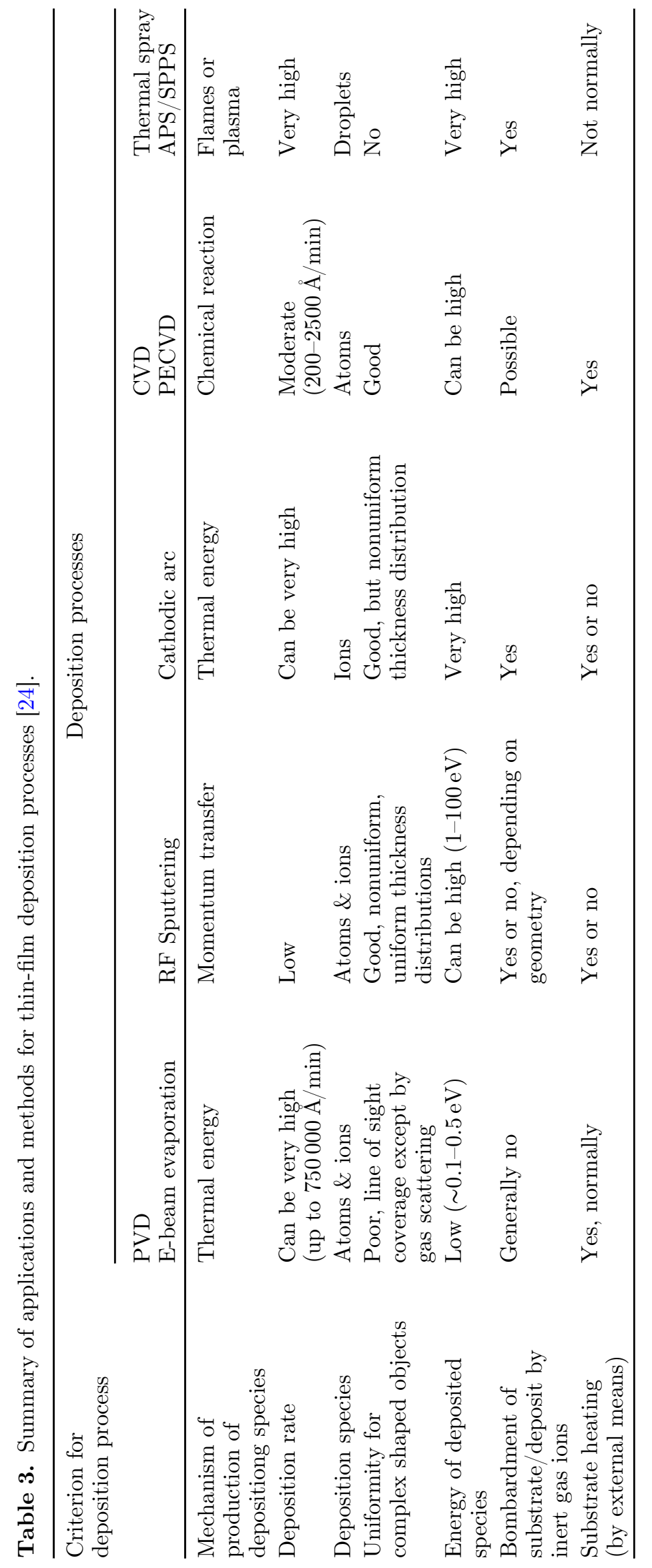




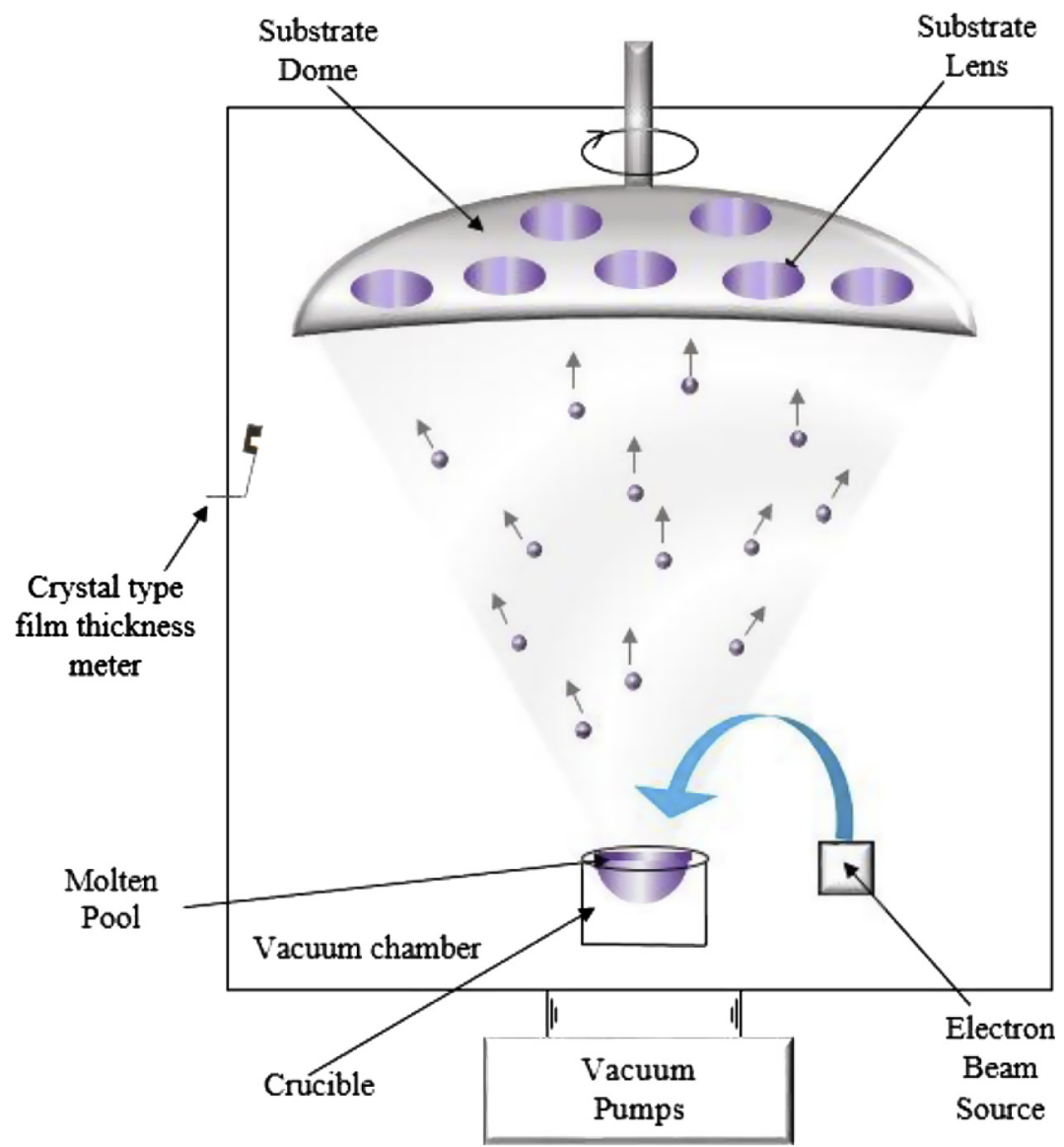

Fig. 4. Schematic of vacuum evaporation process with E-beam heating [25].

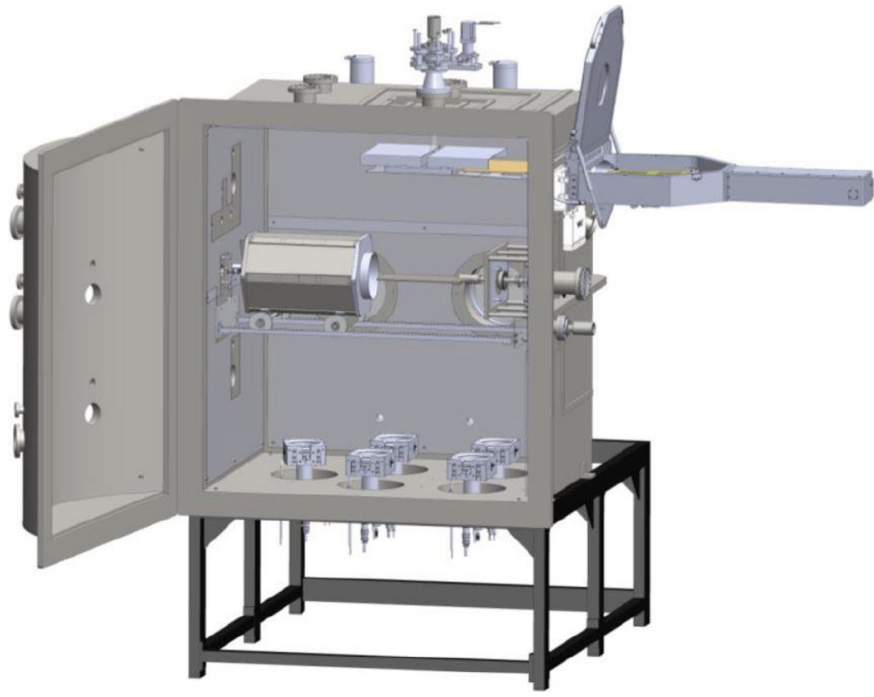

Fig. 5. EB-PVD system with multiple-gun sources [TORR Inc. USA Manual for IMNR EB-PVD System].

materials. Thus, HPPMS can serve as an elegant approach to overcome the shortcomings of conventional techniques. An example of this are the studies undertaken on the deposition of $\alpha-\mathrm{Al}_{2} \mathrm{O}_{3}$ films by HPPMS at a low temperatures $\left(650^{\circ} \mathrm{C}\right)[27]$.
The potential of HPPMS is clearly seen, which explains why currently many industries show interests in it. With HPPPMS, some existing problems with conventional PVD processes could be addressed or even fully resolved for a particular application. At the same time, fundamental understanding of the processes and material deposition mechanism would need to be developed further in order to fully exploit the potential of this technique.

Electron-beam physical vapour deposition (EBPVD) is another method that is able to overcome some problems associated with spray coating, CVD and PVD methods [25], through directly melting and evaporating ingots as well as preheating the substrate by highly focused highenergy electron-beams that are generated from the electron guns (Fig. 5). The EBPVD process takes place in a vacuum chamber. With such a method, a relatively high deposition rate could be achieved, e.g. $150 \mathrm{urn} / \mathrm{min}$ with an evaporation rate of $10 \sim 15 \mathrm{Kg}$ /hour approximately. The coating composition could be easily controlled as well as microstructures; the working environment in a vacuum leads to lower contamination; the focused beam applications results in high thermal-efficiency; with combinations of the process's merits, denser coatings could be achieved. Its control-ability and flexibility means that selectively depositing multi-materials such as metals and ceramics in the forms of multi-layered coatings could be easily implemented: coating oxides, carbides, nitrides, etc. are especially useful for the parts to be used in extreme 


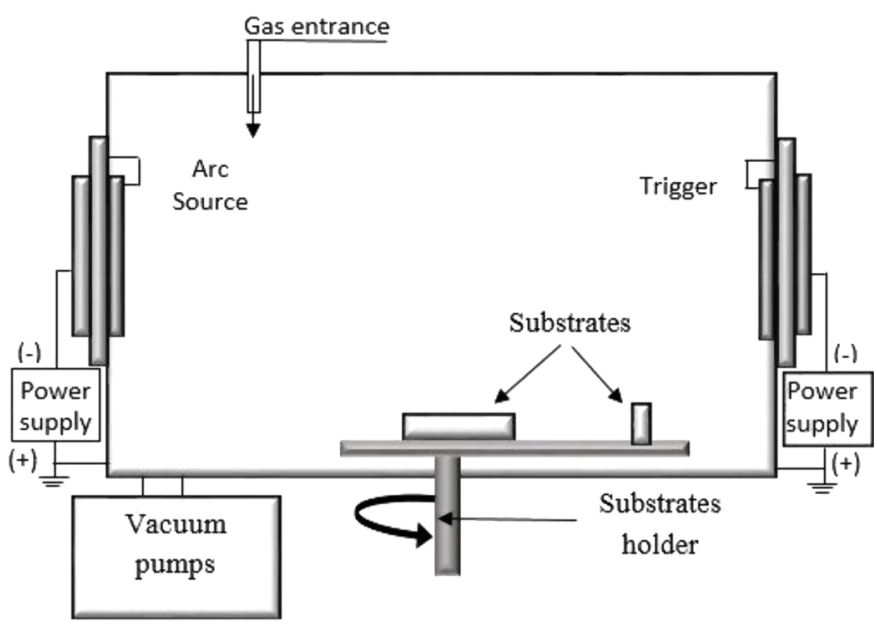

Fig. 6. Schematic of the cathodic-arc evaporation (CAE) PVD [24].

conditions, others including molybdenum, tungsten, and carbon [28]. One more merit is that the process can be carried out in relatively lower temperatures.

Cathodic Arc Deposition is another alternative method for generating a high-velocity jet of the vapourized cathode-material by applying high-current and lowvoltage arc onto the surface of a target material.

\subsection{Chemical vapour deposition (CVD)}

Chemical Vapour Deposition (CVD) has been a popularly used method for producing high-quality coatings. The associated processes are of high flexibilities and able to produce uniform-thickness and low-porosity coatings. Properly selecting material and process parameters such as composition and mixture of the reaction gas, substrate material and working temperature, chamber pressure and gas-flows, required quality and properties (chemical, physical, tribological, etc.) of the coating can be met for various applications, and these can be done for selectively chosen areas such as that on the substrate patterned.

A CVD process may be assisted by heating, e.g. so called thermally activated CVD (TACVD), and the reaction process may actually be induced and maintained by photons, electrons and ions, and their combinations (e.g. CVD activated by plasma). The high vacuum chemical vapour deposition (HV-CVD) is another method further progressing from conventional CVD. The method is particularly useful for the fabrication of thin-films of oxide materials. The process may be considered as a hybrid one involving low-pressure chemical vapour deposition (LPCVD) and molecular beam epitaxy (MBE) [29]. Nevertheless, deposition rates up to $500 \mathrm{~nm}$ per hour have been achieved, indicating substantially higher rates than that achievable with an MBE process, which could lead to several micro-meters thick coatings. The use of lower substrate-temperatures suggests possibilities of incorporating in-situ high-vacuum characterisation techniques into the deposition process, and hence, for better process monitoring and possibly, inline quality control. Further, the molecular-flow deposition regime could allow for uses of hard-masks and lift-off techniques and hence, for in-situ structuring of the films formed. Nevertheless, one of the main challenges for the disposition of some oxides is still to identify an optimal precursor to be a good volatile while the deposition rate is satisfactory in high vacuum.

\section{Thermal spray}

Thermal barrier coatings (TBC) (Fig. 7) are one of the mostly dealt with types of the coatings for the components/ parts used in high-temperature operating environments such as gas turbine aero-engines. The challenges are growing due to the needs to meet demands for higher engine performance and efficiency, including using new component-materials as well as introducing new turbine/component structural designs. Applications of ceramic-matrix composite (CMC) components [30] have also been attempted and are continuously being investigated. The TBCs normally have two layers: ceramic top-coating comprising zirconia ( $\mathrm{ZrO} 2)$ that are "partially stabilised" with yttria (Y2O3), and a boding coating in alumina. The Arc plasma spraying (APS) and solution precursor plasma spray (SPPS) are two methods popularly used for creating thermal barrier coatings (TBC) [31].

Solution precursor plasma spray (SPPS), as shown in Figure 8, involves feeding an aqueous or non-aqueous solution into the plasma to form the coating, and the solution may contain cation(s) for forming the oxide of interest, while in a conventional plasma spray process, a flow of the powder of the coating material is often provided [32]. A similar method to SPPS is so called SPS (suspension plasma spray) in which a liquid with particle suspension is fed into a heated jet. One of the advantages of feeding a feedstock in the liquid form is ability of using smaller particles and hence, producing sub-micron meter and nano-structured coatings, resulting in coating with much better performances.

Although significant effort has been made for producing TBCs for various kinds of applications, producing TBCs with higher performances would need a systematic approach. The effectiveness of the current effort is largely weakened due to lack of good understanding of the failure mechanisms of TBCs in extreme conditions, especially that for new materials, which is further weakened by lack of robust numeric models to support the failure analysis and the, prediction of service life, as well as to support the coating process designs. In-service monitoring and off-line non-destructive testing, materials and coating property characterisation, are the fields needing further attentions. These may apply to all kinds of key coating materials, coating processes and coated products.

\section{Surface modification and functionalisation}

The engineering surfaces produced after a manufacturing process such as casting, machining, forging and extrusion, may not be adequately good to meet applications in specific environment. To enhance or alter surface properties for particular applications, besides that these surfaces may be treated with thin-film depositions, as described and 


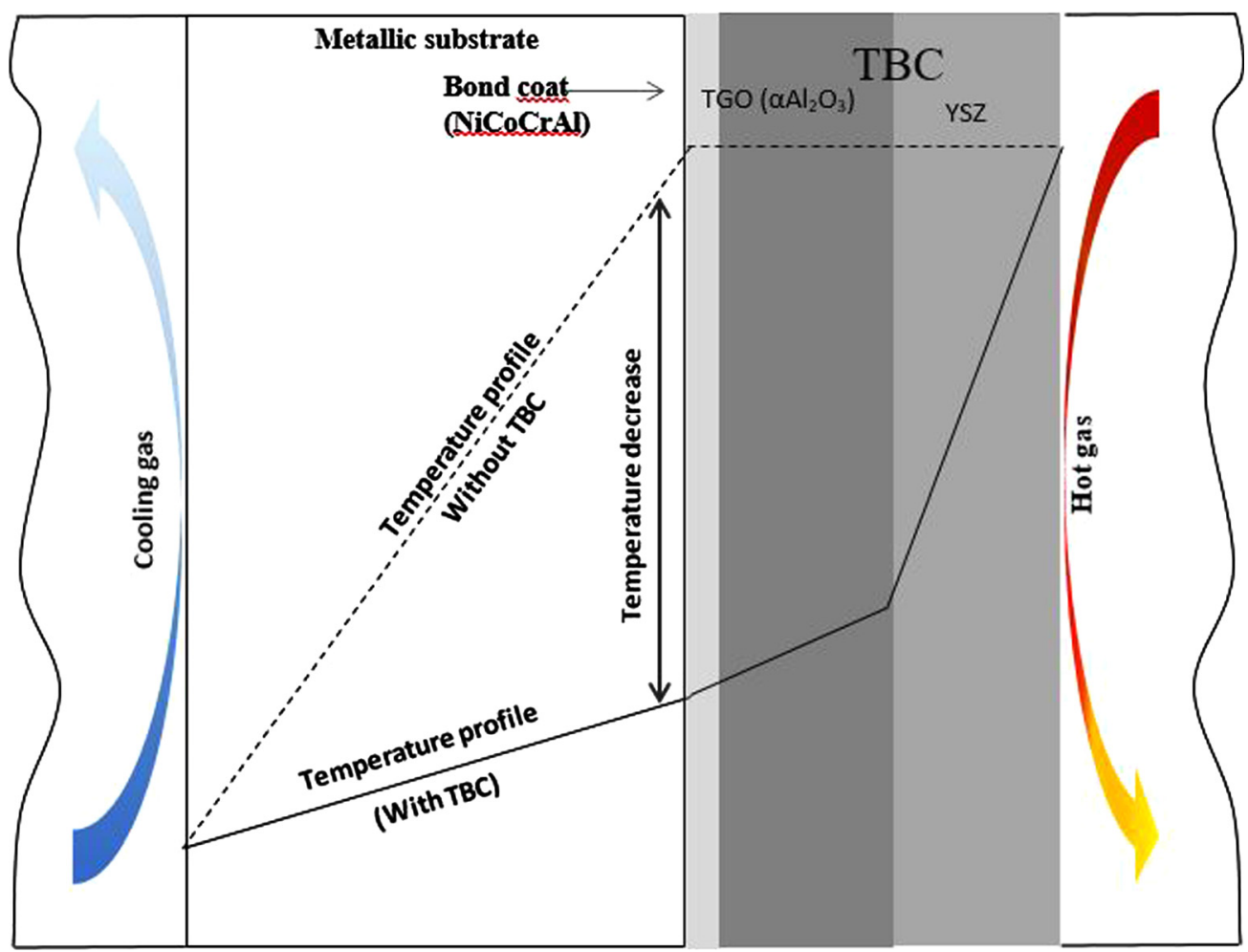

Fig. 7. Schematic representation of a thermal barrier coating.

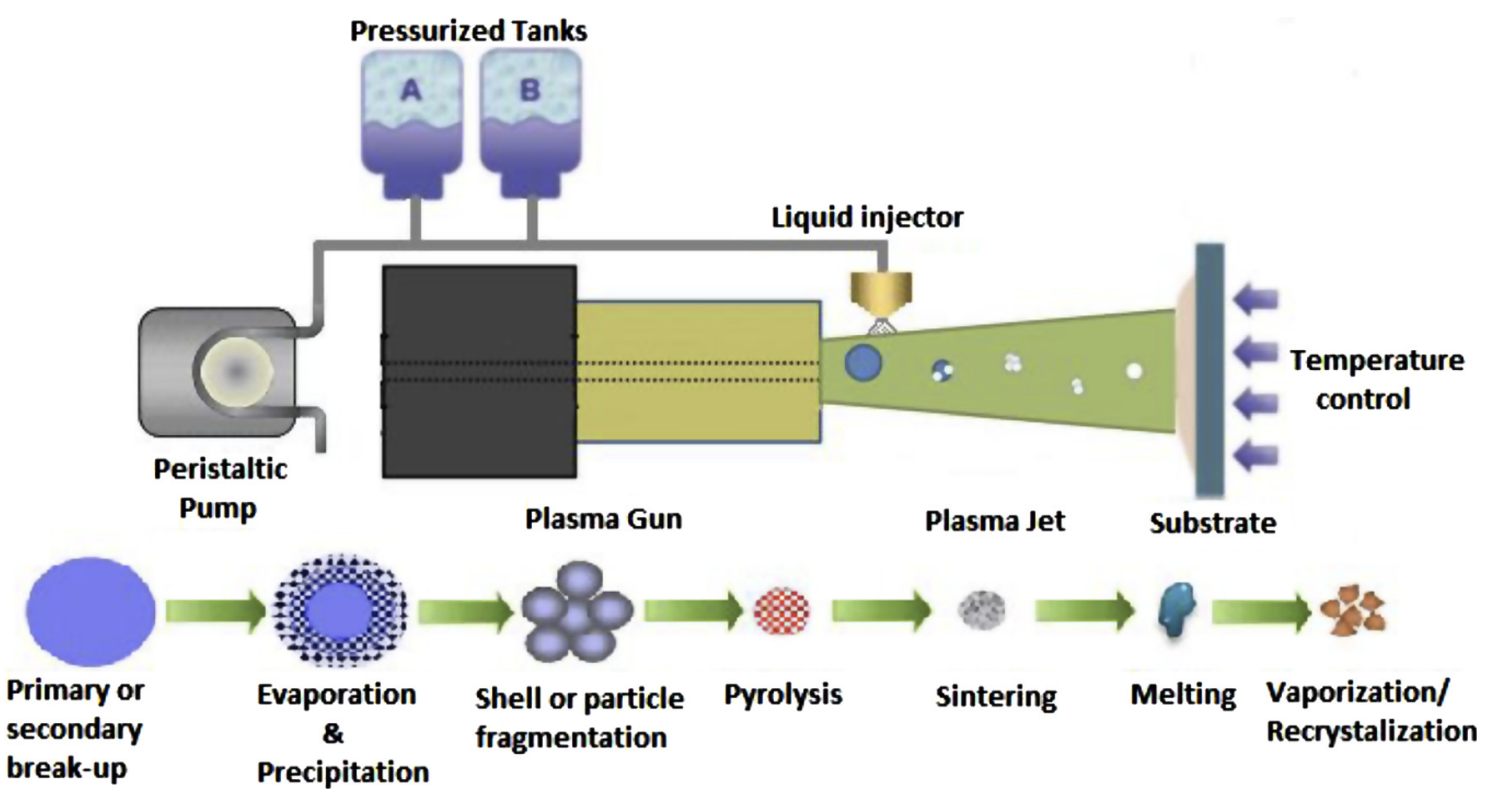

Fig. 8. Schematic of SPPS [33].

discussed above, these may be treated directly, without need to add a coated layer. The relevant techniques include plasma nitriding of steels, laser alloys, laser-beam case hardening, etc. which would increase the surface hardness and/or add new functionalities. The combined uses of surface treatments for applications in extreme conditions such as high-temperature hot-forming, high-friction and high-wear, etc. were further reported in the literatures
$[34,35]$. The surfaces' mechanical, thermal, optical, biomedical and magnetic properties could also be modified through using other techniques such as surface texturing/ patterning by laser ablation, focused ion-beam and electron-beam. Other mass-production techniques include micro/nano hot-embossing, roll-to-roll cold and warm forming, micro injection moulding, photo-electro-forming, etc. 
Latest efforts include taking advantages of modern chemistry, nano-materials (unique mechanical and physical properties), and ever-updated capabilities of nanotechnologies to create special functionalities over the structural part surfaces to meet different kinds of application requirements, typically, functionalities for anti-corrosion, self-diagnosis/sensing, self-healing, selflubrication and self-cleaning.

Through manipulating a coating matrix, such as molecular structures and/or chemical compositions, e.g., that based on polysiloxane chemistry, high-performance anti-corrosion coatings could be produced, while flexible chemistry of siloxanes would allow for creating surfaces with functionalities such as ice-repellence, super-hydrophobicity, and self-cleaning.

Including bulk and/or surface functional groups in the coating matrix composition and/or encapsulation of functionally active species in host carriers may lead to the development of high-performance anti-corrosion surface-systems [36], adding smartness to the surface performances. Such an approach would allow for using the encapsulation of functional agents for self-healing to develop coatings with self-healing capabilities [37]. For example, combined uses of different carriers/structures (e.g., capsules, hollow-particles, mesoporous particles, layered-clays or tubular reservoirs) containing healing or functional species which are sensitive to different stimuli and loadings, and hence, respond to different kinetics of release, would allow for the development smart coatings with multi-functionalities, notably, self-healing, antifouling and super-hydrophobic coatings [38]. A sol-gel route and use of silica particles (porous, mesoporous, hollow, functionalised, etc.) would enable to achieve superhydrophobicity that would enhance anti-fouling protection [39].

Similar approaches have been adopted by many researchers in order to develop smart materials and surfaces, but these are, mostly, still in conceptual or prototyping stages. Complex issues around these developments need to be addressed fully, including: reliability of the smartness of these materials and structured coatings; robustness of the performances of the material and coatings when used in service conditions; processes relating to the manufacture of products that would allow mass-producible with a level of the cost acceptable by the customers. These apply to the development of stimuli-responsive polymeric or inorganic carriers for smart materials and surfaces.

\section{Multiscale Modelling supporting development of multi-layered coatings}

Advanced surface coatings, especially multi-layered coatings, are still effective and efficient technologies to meet engineering needs and challenges. Nevertheless, these developments could be accelerated if more effective and efficient modelling techniques could be provided. Although there were various modelling techniques having been developed to assist the analysis of the coating processes and performances of the coated surfaces, there has been an urgent need for further developing these techniques that can support design and manufacture of advanced surface systems more accurately and more efficiently. The EU FP7 M3-2S project was to address the urgent scientific, technological and market need for consistently reliable, high performance multi-layered surface systems, by developing generic, robust multiscale materials modelling techniques [40,41]. These covered the range from nano, through micro to macro-scales (Fig. 9), for the design, optimisation and performance prediction of multilayered surface systems such as $\mathrm{TiN}$ and $\mathrm{TiC}$ coatings, for a wide range of engineering applications, including:

\subsection{Atomic-scale modelling}

Molecular dynamics simulations [41,42] of the physical vapour deposition of the multilayered surface coatings. MD simulations were also used to determine drag coefficients for dislocation motion and for discrete dislocation simulations (DD) used to calibrate the hardening law needed for crystal plasticity (CPFE) simulations in the micro-scale modelling. Atomistic First-Principles Calculations [41], [43] were carried for the analysis of mechanical property constants and interfacial adhesion to support the coating designs and modelling at the higher length-scales.

\subsection{Nano-scale modelling}

An atomic finite element (AFE) model [44] was developed based on the atomic structures determined by MD for the multilayered surface coatings, which was to bridge between the MD and Continuum Mechanics.

\subsection{Micro-scale modelling}

Crystal plasticity analyses were coupled to the nano-scale AFE simulations and the macro-scale finite element simulations. The crystal plasticity analyses [45] were in some cases informed by discrete dislocation calculations. New hardening and damage equations were developed accordingly for such modelling.

\subsection{Macro-scale modelling}

Parametric continuum finite element (FE) modelling [46] was carried out, coupled to the crystal plasticity calculations at the micro-scale and serve as the first step in the submodel calculations (macro to atomic).

These represented new modelling techniques that are able to support the coating designs and coating performance analysis.

\section{Examples of the materials and functional coatings for applications in extreme conditions}

In this section some examples of real material systems and types of the coatings used in service under extreme environments are described. 


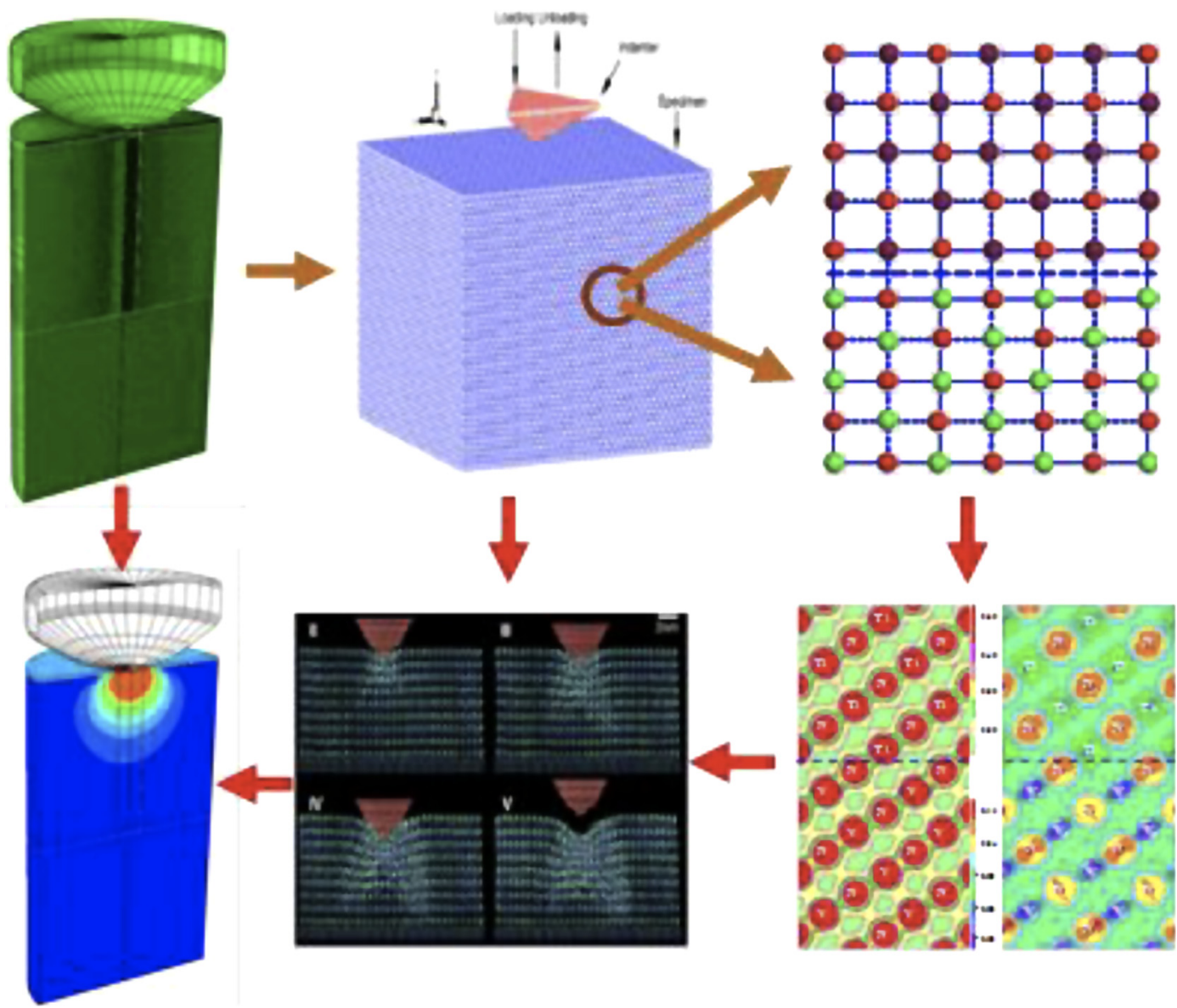

Fig. 9. Schematic of numerical simulations from Macro-, Micro- to Nano-scale for the analysis of multi-layered coatings [41].

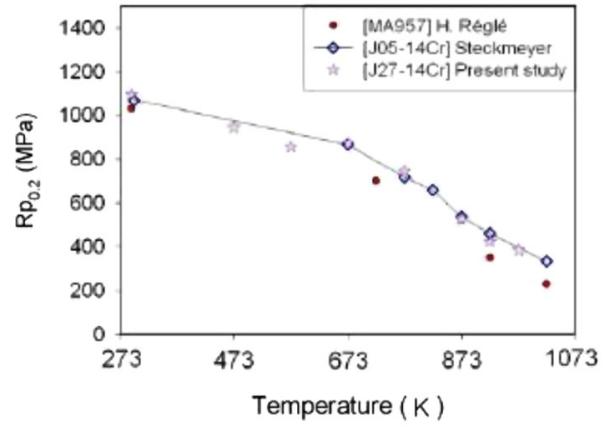

(a)

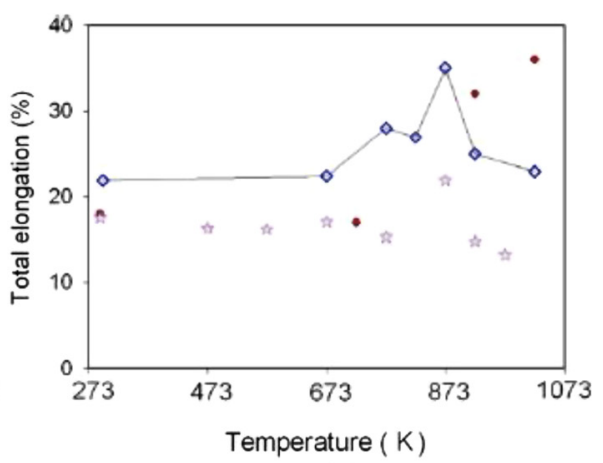

(b)

Fig. 10. Longitudinal (a) yield stress and (b) total elongation as a function of temperature for the CEA ODS steels compared to the commercial MA957 steel [48].

\subsection{Oxide dispersion strengthened ferritic steels}

Oxide Dispersion Strengthened (ODS) ferritic steels are candidate materials for cladding fuel-tubes in Generation IV nuclear reactors [47]. The oxide particles dispersed in the steel alloy matrix, using mainly powder metallurgy processes, reduce movement of the dislocations within the material and in turn, prevent creep to occur.

A range of mechanical property tests was undertaken on three different ferritic ODS steels produced at CEA [48] - one of the partners of the EU SUPERMAT project consortium who conducted this review, to determine tension, creep, fatigue, impact/toughness and anisotropy characteristics of the steels.

Considering the fact that these materials are often used in tubes subjected to high internal pressure, anisotropy needs to be addressed. The complex thermomechanical process, leading to the final geometry, significantly modifies the microstructure, potentially reduces the anisotropy. Nevertheless, achieving high mechanicalintegrity of the cladded tubes remains a key issue being addressed in nuclear design. 
In the mechanical tests including tension, creep, impact and toughness tests, intergranular fracture and significantly weakened grain-boundaries aligned along the extrusion direction were observed. The orientation of the grain boundaries was thought to be a main reason causing anisotropy of the damage.

The very high Norton exponent (constant within the $873 \sim 973 \mathrm{~K}$ temperature range for a given material) was observed in the tensile creep tests, suggesting existence of a threshold stress. This is consistent with the predominant kinematic nature of the stress partition obtained in the fatigue tests.

Steckmeyer et al. [49] reported how tensile tests carried out between $20^{\circ} \mathrm{C}$ and $750{ }^{\circ} \mathrm{C}$ on a $14 \mathrm{Cr}$ ferritic steel (J05) have highlighted two types of anisotropy, which are directly linked to the microstructural orientation produced after hot-extrusion. The first is a strong longitudinal/ transverse anisotropy, with a transverse ductility being half the axial ductility. It has been largely discussed in literature and appears to be related both to the grain morphology and to the presence of the grain boundary particles.

The second type of anisotropy is a yield stress anisotropy, which has been shown to be temperature dependent. Several strengthening mechanisms that may account for such mechanical anisotropy have been reported.

Regardless those issues, Oxide Dispersion Strengthened (ODS) ferritic steels offer attractive applications for high corrosion-resistance components with complex shapes and high dimensional-accuracy. The components, for example, could be manufactured using additive manufacturing methods such as selective laser sintering and spark plasma sintering.

\subsection{Fire-resistant and insulating coatings}

Fire protection of the products/parts made from various kinds of materials such as steels, woods, plastics, elastomers, has been studied intensively in the past, and various kinds of protection measures and products have been evolved. New coatings or improved performances of the existing coatings are needed due to demands for higher standards for protections [50], for example, protective coatings deposited on a metal substrate [51] and utilising preceramic-polymers and inorganic-fillers, making these refractory.

Analysis of the relationships between polymer structure, composition and fire behaviour are critical to understanding thermal decomposition and fire-resistant mechanisms of polymers and tests will lead to mechanism identification and design of new fire-safe polymeric materials. Studies have revealed a global composition able to form a glass from silica with ceramic fillers for fire resistance. Together with abrasion and erosion resistance, composition may be varied to adjust thermomechanical behaviour.

Rheological evaluation tests are needed to assess the influence of viscosity on the thickness of deposit. The effects of different deposition methods on surface characteristics should be examined in order to produce coatings that fulfil fire and erosion tests.

\subsection{Self-healing coatings for corrosion protection}

Chromate-rich surface-treatments and/or primers and pigments based on chromates are often used for corrosionprotection surfaces. The legislation imposed by REACH (Registration, Evaluation, Authorisation and Restriction of Chemicals), however, now prohibits uses of hexavalent chromium, except that used in the aerospace industry. The concept of self-healing in corrosion protection is latest one that has attracted attentions. Pre-treatment layers, primers and topcoats could be treated for different functionalities, through including different corrosion-inhibiting species. These could be either added directly to a coating or by embedding them in containers which would be responsive to special triggering stimuli. A coating-matrix formulation for such a purpose of applications, for example, can be prepared through a sol-gel reaction of tetraethyl orthosilicate (TEOS) in the presence of a polysiloxane, subsequently adding an adhesion promoter into it. The formulation and microcapsules were then mixed, resulting in a self-healing coatingformulation. A use involved spraying of the coatingformulation onto the surface of a board made of cellulosefiber-reinforced-cement and a motar [52]. It was revealed that the healing agent could be released from the ruptured microcapsules and then filled the are where the damage occured, and a sunlight-induced self-healing capability was also demonstrated during the tests on the motar.

\subsection{CAE-PVD coatings of the forming tools used in high-temperature powder sintering}

Micro-FAST is an innovative process combining Eletricfield-activated sintering technqiue with micro-forming of powders for the forming of miniature/micro-components from various kinds of powders, including metal alloys, MMCs and ceramics. The working temperature in a powder could be in a range of a few hundred degrees to more than one thousand degrees (e.g., $1300 \sim 1400^{\circ} \mathrm{C}$ ), depedning on the type of the material to be formed [53]. One of the challenges to the process realisation is to find right formingtool material that has sufficient high-temperature strength and toughness. Titanium-zirconium-molybdenum allows (TZM) was proposed for uses initially, and oxidation under high-tempeatures is, however, a major concern for such a material as a forming-tool material.

AIN in spain - one of the core partners in the EU FP7 Micro-FAST project, has developed an CAE-PVD coating procedure to deposite multi-layered $\mathrm{CrAlO}$ and $\mathrm{CrAlO} /$ CrAlN coatings over the TZM-tool surfaces [54] as protective films. Such films were examined and tested in their composition, microstructure, mechanical properties and thermal stability in the air, at the high-temperatures $\left(800 \sim 1100^{\circ} \mathrm{C}\right)$, and tribological behavour at $400^{\circ} \mathrm{C}$. Hardeness of $25 \sim 30 \mathrm{GPa}$ has been achieved with those films, and it was shown that the multilayered coatings exhibited good mechanical-stability at $1100{ }^{\circ} \mathrm{C}$ and excellent behaviour against wear at $400^{\circ} \mathrm{C}$. The sintering trials for the forming of Ti90Sn10 and Al2O3 powder with the coated tools showed very promising results against wear, sticking and oxidation of the tool surfaces [54]. 


\section{Conclusions}

Developing systems with capabilities of resistance to extreme conditions has proved to be able to neutralise the effects of extreme conditions and to improve the resistance of the material systems and structures that are used in harsh environments.

Protective coatings and surface treatments that functionalise surfaces have been proven to be excellent means for counteracting extreme conditions. There have been many options available for obtaining the required coatings and functionalised surfaces, and these could be used in tailored forms to meet specific needs.

The ever-increased demands for new functional films and coatings and improved performances of existing ones have been significant incentive for the research and technological developments towards not only new understanding of the fundamentals and optimisation of the technical aspects of thin film growths but also developing new deposition techniques, such as CDV, DV, new thermal spray, and all corresponding processes.

Research in smart coatings/structures for functional surfaces for combating extreme conditions has resulted in some promising results towards self-healing, especially that for anti-corrosion. This is a field further needing significant effort, in terms of achieving more robust performances from these designed structures, avoiding possible, negative effects on the overall properties and performances of the original materials and structures, ensuring to be producible in large-scale production, and reducing overall development costs, etc.

To assess effectiveness of the process control and ensure meeting specific requirements of applications of each material system, more reliable testing and surface characterisation, e.g., mechanical tests at extreme conditions, such as under high temperatures and in specific environments, such as $\mathrm{H} 2, \mathrm{Na}$, radiations, etc., should be undertaken.

Developing more robust process modelling, surface modelling, and design optimization, is required in order to obtain coatings, films and surfaces with controlled microstructure, phase distribution and special functionalities for specific harsh environmental conditions. This is a field needing increased effort, if the real "material/coating development by design" could be achieved and corresponding process control can be realised with the reduced cost.

All authors acknowledge the financial support from H2020 Grant Agreement TWINNING 692216 "The virtual Center for sustainable development of Advanced Materials operating under extreme conditions"- Acronym SUPERMAT.

Authors Radu R.Piticescu and Santiago Cuesta-Lopez acknowledge the COST Action "Solutions for Critical Raw Materials under Extreme Conditions", supported by COST (European Cooperation in Science and Technology).

Authors Radu.R.Piticescu, Arcadii Sobetkii and Anca E. Slobozeanu also ackowldege the financial support from the grant of the Romanian Ministry of Research and Innovation, RDI Programe for Space Technology and Avanced Research - STAR, project number 528 (Acronym Androtech).

\section{References}

1. P. French, G. Krijnen, F. Roozeboom, Microsys. Nanoeng. 2 (2016)

2. Office of Basic Energy Sciences, U.S. Department of Energy, Report of the basic energy sciences workshop for materials under extreme environments, 2008

3. N. Simos, Composite Materials/Book 2, InTECH Open Access Publisher, 2011

4. A.H. Lettington, Carbon 36 (1998) 555-560

5. M. Salvo, V. Casalegno, S. Rizzo, M. Ferrairs, A. Ventrela, F. Smeacetto, Book Chapter, in: Advances in Brazing, 2013, $525-544$

6. A. García-Arribas, J. Gutiérrez, G.V. Kurlyandskaya, J.M. Barandiarán, A. Svalov, E. Fernández, A. Lasheras, David de Cos, I. Bravo-Imaz, Sensors (Basel) 14 (2014) 7602-7624

7. Annual Global Cost of Corrosion, Engineering 360 News Desk 21, 2016

8. http://energyskeptic.com/2016/corrosion-eats-552-billioninfrastructure-per-year-6-pct-of-gdp-billion-cost-per-year-6of-gdp/

9. Ali Erdemir, FME Transactions, 43 (2015) 181-185

10. http://professional.mit.edu/programs/short-programs/tri bology

11. http://www.southampton.ac.uk/engineering/research/im pact/preventing_wear_and_tear.page

12. IK4 TEKNIKER Tags News, 2015

13. A. Pesaran, S. Santhanagopalan, G-H. Kim, $30^{\text {th }}$ Int. Battery Seminar, 2013, NREL/PR-5400-58145

14. M.C. Smart, B.V. Ratnakumar, JES 158 (2011) A379-A389

15. P. Lall, M.G. Pecht, E.B. Hakim, Influence of Temperature on Microelectronics and System Reliability, CRC Press, New York, 1997, p. 322

16. S. Dubey, J.N. Sarvaiya, B. Seshadri, Energy Procedia 33 (2013) 311-321. The PV Asia Pacific Conference 2012

17. E.J. Oughton, A. Skelton, R.B. Horne, A.W.P. Thomson, C. T. Gaunt, Space Weather 15 (2017) 65-83

18. M. Hapgood, et al., Science and Technology Facilities Council, 2015, http://eprints.lancs.ac.uk/64441/, accessed 2015-06-25

19. Space Studies Board, A workshop report [online], Natl. Academies Press, Washington, D.C., 2009

20. C.J. Schrijver, et al., Adv. Space Res. 55 (2015) 2745-2807

21. J.P. Eastwood, et al., Risk Anal. 37 (2017) 206-218

22. A. Eder, et al., Phys. J. D 70 (2016) 247, DOI: 10.1140/epjd/ e2016-70435-7

23. K. Sarakinos, J. Alami, S. Konstantinidis, Surf. Coat. Technol. 204 (2010) 1661-1684

24. Peter M. Martin, Handbook of Deposition Technologies for Films and Coatings, Third Edition, Elsevier, 2010

25. R. Prabu, S. Ramesh, M. Savitha, M. Balachandar, Proc. of the International Conference on Sustainable Manufacturing, 427, 2013

26. https://www.researchgate.net/publication/223532355_High power_pulsed_magnetron_sputtering_A_review_on_scien tific and engineering state of the art.

27. Y. Ȳamad̄a-Takamura, F. Koch, H. Maier, H. Bolt, Surf. Coat. Technol. 142 (2001) 260

28. https://www.researchgate.net/publication/237282854

29. Y. Kuzminykh, A. Dabirian, M. Reinke, P. Hoffmann, Surf. Coat. Technol. 230 (2013) 13-21

30. R. Darolia, Int. Mater. Rev. 58 (2013) 315-348 
31. A. Ganvir, N. Curry, S. Govindarajan, N. Markocsan, Int. J. Appl. Ceram. Technol. 13 (2016) 324-332

32. E.H. Jordan, C. Jiang, M. Gell, J. Therm. Spray Technol. 24 (2015) 1153-1165

33. A. Vardelle, et al., J. Therm. Spray Technol. 25 (2016) 13761440

34. Z.X. Zhang, H.S. Dong, Manuf. Rev. 1 (2014) 24

35. G.G. Fuentes, E. Almandoz, R.J. Rodríguez, H.S. Dong, Y. Qin, S. Mato, F.J. Pérez-Trujillo, Manuf. Rev. 1 (2014) 20

36. M. F. Montemor, Surf. Coat. Technol. 258 (2014) 17-37

37. M. Plawecka, D. Snihirova, B. Martins, P. Warszynski, M.F. Montemor, Electrochim. Acta (2014)

38. C.H. Zhou, Z.F. Shen, L.H. Liu, S.M. Liu, J. Mater. Chem. 21 (2011) 15132-15153

39. U. Kharchenko, I. Beleneva, Corros. Sci. 72 (2013) 47-53

40. Y. Qin (ed.), A special issue in the J. Multiscale Model. 3 (2011).

41. D. Yin, Z. Xu, J. Feng, Y. Qin, Manuf. Rev. 1 (2014) 1-14

42. Z.H. Xu, L. Yuan, D.B. Shan, B. Guo, Comput. Mater. Sci. 50 (2011) 1432-1436

43. D. Yin, X.H. Peng, Y. Qin, Z. Wang, Ceram. Int. 41 (2015) 10095-10101D

44. R. Neugebauer, R. Wertheim, U. Semmler, J. Multiscale Model. 3 (2011) 39-48
45. S. Wang, W. Zhuang, J. Cao, J.G. Lin, Chapter 32 in: Yi Qin (ed.), Micro-Manufacturing Engineering \& Technology, Elsevier, Oxford, 2015

46. J. Feng, Y. Qin, R.R. Koodakal, J. Michler, Proc. of the Institution of Mechanical Engineers, Part B, J. Eng. Manuf. 226 (2012) 1205-1212

47. X.Q. Cao, R. Vassen, D. Stoever, J. Eur. Ceram. Soc. 24 (2014)

48. A. Kimura, H. S. Cho, N. Toda, R. Kasada, K. Yutani, H. Kishimoto, N. Iwata, S. Ukai, M. Kisimoto, J. Nucl. Sci. Technol. 44 (2007) 323-328

49. B. Fournier, et al., J. Nucl. Mater. 430 (2012) 142-149

50. C. Pagella, R. Epifani, G. Baldi, European Coatings 84 (2008) 17-29

51. B. Schmucki, G. Parcianello, K. Bayard, U. Vogt, J. Dahm, 2015 Dispersions for preparing a fire-resistant protective and insulating coating EP 2784112 A1

52. Young-Kyu Song et al., ACS Appl. Mater. Interfaces 5 (2013) 1378-1384

53. Y. Qin, et al., Procedia Eng. 207 (2017), 1212-1217, ICTP2017 Conference, Cambridge, UK

54. E. Almandoz, et al., Mater. Chem. Phys. 208 (2018) 189-197

Cite this article as: Marina Urbina, Antonio Rinaldi, Santiago Cuesta-Lopez, Arcadii Sobetkii, Anca Elena Slobozeanu, Peter Szakalos, Yi Qin, Mythili Prakasam, Radu-Robert Piticescu, Cedric Ducros, Alain Largeteau, The methodologies and strategies for the development of novel material systems and coatings for applications in extreme environments - a critical review, Manufacturing Rev. 5, 9 (2018) 